\title{
ПРАКТИКА ИСПОЛЬЗОВАНИЯ БЕСПИЛОТНЫХ ЛЕТАТЕЛЬНЫХ АППАРАТОВ ПРИ ПРОИЗВОДСТВЕ ТОПОГРАФИЧЕСКИХ СЪЕМОК
}

\section{Ирина Анатольевна Басова}

Тульский государственный университет, 300600, Россия, г. Тула, пр. Ленина, 92, доктор технических наук, зав. кафедрой геоинженерии и кадастра, тел. (4872)73-44-28, e-mail: biajis20051@ya.ru

\section{Павел Валерьевич Анисимов}

ООО «Верста», 300600, Россия, г. Тула, ул. Демонстрации, 1Г, инженер-геодезист, тел. (4872)52-45-00, e-mail: pashka.anisimov@yandex.ru

В статье приведен опыт применения сверхлегкого квадрокоптера для создания актуализированных топографических планов, инвентаризации труднодоступных территорий. Практика показывает рентабельность применения новых технологий и повышения эффективности кадастровых работ.

Ключевые слова: топографическая съемка, аэрофотосъемка, беспилотные летательные аппараты, геодезическая сеть, фотоплан, топографический план

\section{PRACTICE OF USING UNMANNED AERIAL VEHICLES IN PRODUCTION OF TOPOGRAPHIC SURVEYS}

\section{Irina A. Basova}

Tula State University, 92, Lenin Ave., Tula, 300600, Russia, D. Sc., Head of the Department of Geoengineering and Cadastre, phone: (4872)73-44-28, e-mail: biajis20051@ya.ru

\section{Pavel V. Anisimov}

LLC «Versta», 1G, Demonstration St., Tula, 300600, Russia, Engineer-Surveyor, phone: (4872)52-45-00, e-mail: pashka.anisimov@yandex.ru

The article presents the experience of using an ultralight quadcopter to create actalized topographic plans, inventory of hard-to-reach areas. Practice shows profitability of application of new technologies and increase of efficiency of cadastral works.

Keywords: topographic survey, aerial photography, unmanned aerial vehicles, geodetic network, photoplane, topographic plan

Современное геодезическое обеспечение инженерных изысканий, проектирования и строительства различных объектов, а также инвентаризации, кадастра и оценки объектов недвижимости базируется на использовании принципиально новых геодезических приборов и технологий, географических информационных систем, пространственных баз данных. Большинство полевых измерений и съемок выполняются электронными приборами с автоматической регистрацией и обработкой результатов [1].

Получение данных об исходном земельном участке, такие как: характер рельефа и высотные отметки, расположение наземных и подземных объектов, коммуникаций, определение координат точек в местной или государственной 
системе координат, как правило, получают по результатам, топографических и кадастровых съемок [2].

Сравнительно недавно создание и обновление топографических карт и планов выполнялось по результатам аэрофотосъемочных работ [3].

Аэрофотосъемка в крупных масштабах в масштабе 1:10 000 и крупнее выполнялась на малых высотах, что усложняло ведение детальной визуальной ориентировки, увеличивало влияние на точность проложения аэросъемочных маршрутов погрешностей пилотирования, непостоянства параметров ветра в приземном слое, что повышало требования к точности проложения аэросъемочных маршрутов.

Эти факторы отрицательно влияли на фотограмметрическое качество аэрофотоматериалов, усиливали сдвиг изображения, увеличивали разномасштабность снимков и т.д. и делали съемку мало рентабельной, особенно на небольших территориях [3].

Обработка аэрофотосъемки для получения ортофотоплана также представляла собой достаточно сложный процесс, для которого необходимы специальные знания и оборудование.

В настоящее время для оперативного проведения аэрофотосъемки, радиовещания, поисково-спасательных работ, разведки и наблюдения, поддержания правопорядка и т.д. используют беспилотные летательные аппараты (БПЛА), как в гражданских, так и в военных целях.

Развитие технологии аэрофотосъемки беспилотными летательными аппаратами позволило по своим точностным характеристикам соответствовать классическим способам геодезической съемки для получения крупномасштабных планов.

К основным достоинствам аэрофотосъемки БПЛА можно отнести оперативность получения топографической съемки местности в цифровом виде с хорошей точностью.

Беспилотные летательные аппараты принято классифицировать по массе, времени работы, дальности и высоте полета.

По этим параметрам выделяют 4 класс БПЛА:

- сверхлегкие аппараты (до 10 кг), время полета около 1 ч, высота полета до 1 км;

- легкие (до 50 кг), время полета несколько часов, высота до 3-5 км;

- средние (до 1000 кг), время полета 10-12 ч, высота до 9-10 км;

- тяжелые - высота полета до 20 км, время полета 24 ч и более.

В 2019 году при выполнении кадастровой съемки выполнялась аэрофотосъемка для текущей инвентаризации территории в г. Москва и для подготовки проекта реконструкции линии электропередач на земельных участках, доступ к которым был ограничен в д. Никитино-Калужской области (рис. 1). 


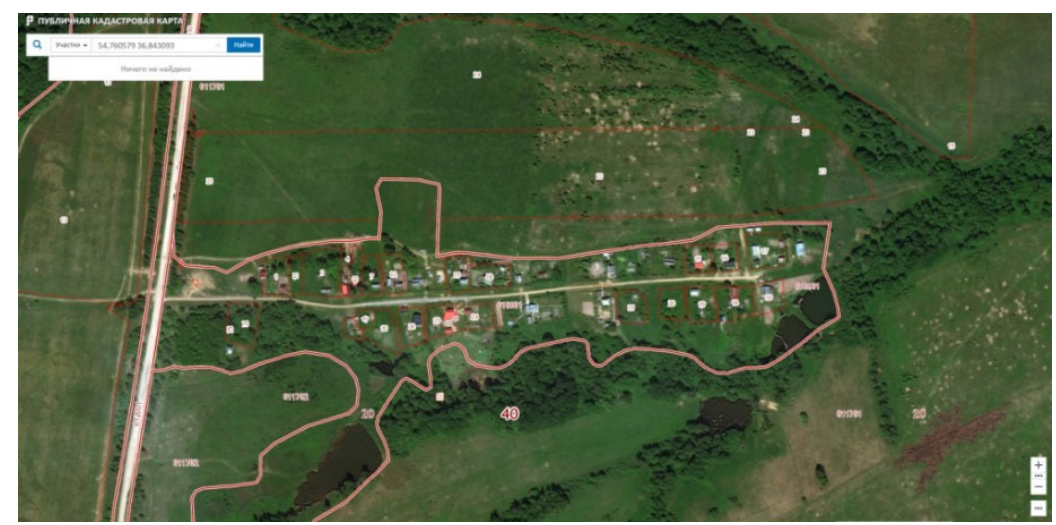

Рис. 1. Территория для съемки на публичной кадастровой карте в Калужской области

Съемка выполнялась сверхлегким квадрокоптером Phantom 4 Pro, который имеет наименьшую стоимость среди аналогичных. Максимальное время полета составляет около 30 минут при достаточно большом диапазоне рабочих температур (от 0 до $+40{ }^{\circ} \mathrm{C}$ ), максимальная скорость 2 км/ч. Максимальная высота полета для выполнения ситуационного снимка составила 150 метров и удаленность от радиоуправляемого пульта 3500 метров (рис. 2).

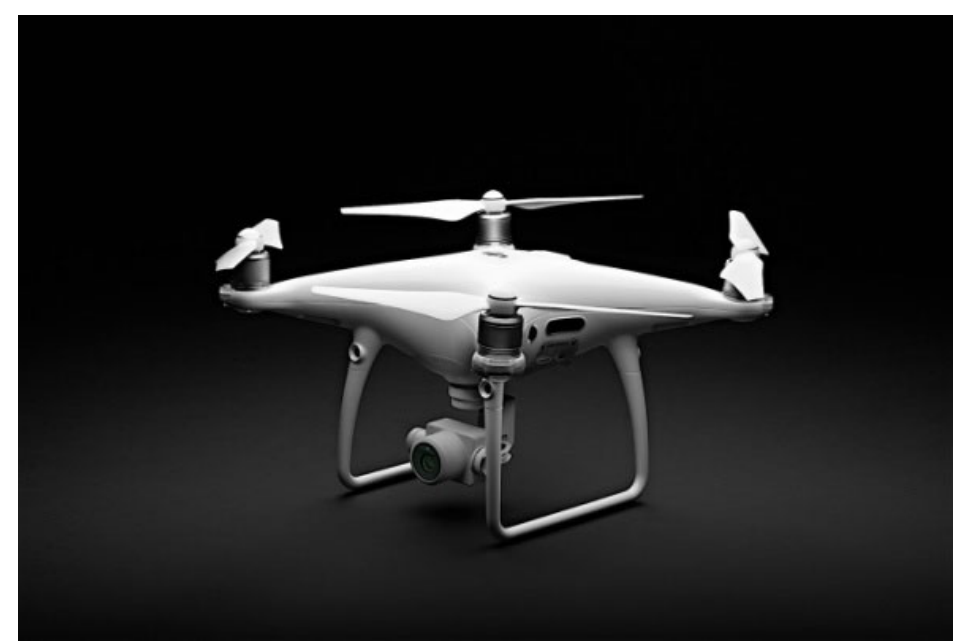

Рис. 2. Квадрокоптер Phantom 4 Pro

Ширина одного снимка зависит от высоты полета беспилотника. При высоте полета 75 метров захват территории камерой составил 16х16 метров, при высоте 60 метров размер снимка - 13,7х13,7 метра.

Построение маршрута для облета территории выполнялось в программе DroneDeploy. Маршрут полета, время на его выполнение, площадь полета, плотность фотографий для более четкого итогового изображения рассчитываются в автоматическом режиме и зависят от высоты полета и нужного разрешения карты (рис. 3). 

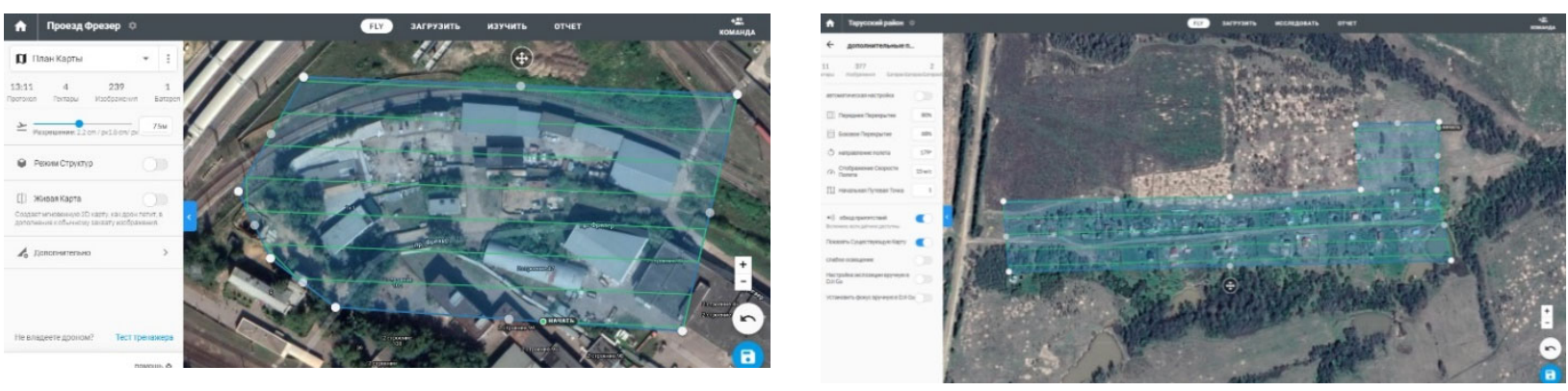

Рис. 3. Маршруты полета беспилотника над заданным местом

Маршруты аэрофотосъемки проектировались с продольным и поперечным проектированием, с возможностью максимально большего числа пунктов существующей геодезической сети использовать в качестве опорных при обработке снимков.

Обработка общего аэрофотоплана выполнялась по трансформированным аэрофотоснимкам. Трансформирование снимков выполняется в программе DroneDeploy (рис. 4 и 5).

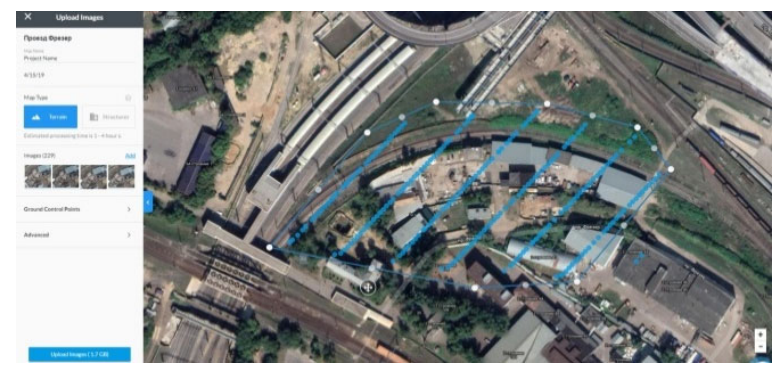

Рис. 4. Загрузка фотографий, полученных при облете территории

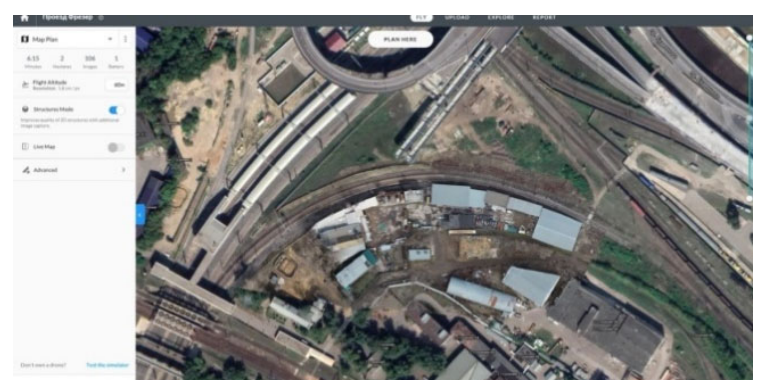

Рис. 5 Готовый аэрофотоплан в программе DroneDeploy

Полученный в результате обработки фотоплан территории использован в качестве подложки для топографической съемки тахеометром SpectraFocus 2" (г. Москва) и спутниковым оборудованием Trimble R8s (рис. 6 и 7) [4].

a)

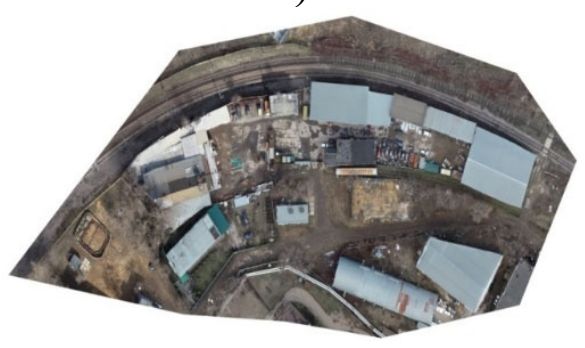

б)

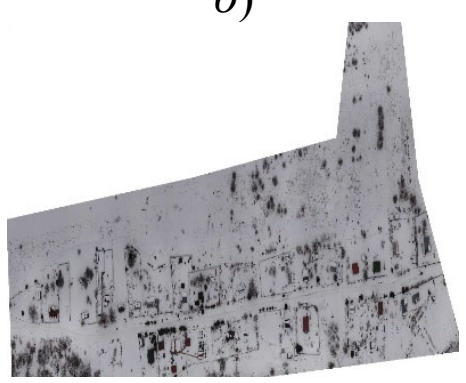

Рис. 6. Фотоплан территории: $a$ ) территория в г. Москва; б) территория в Калужской области 
a)

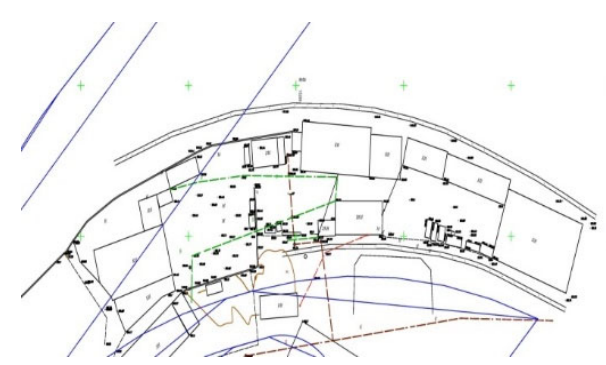

б)

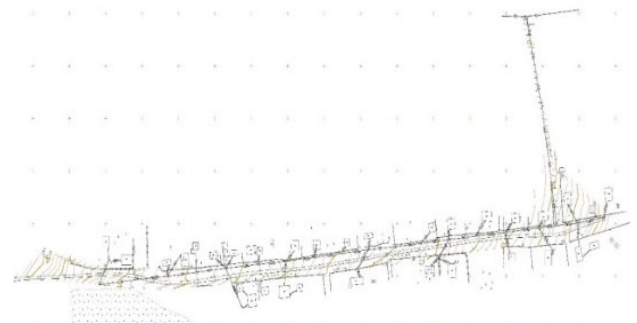

Рис. 7. Топографическая съемка территории: a) территория в г. Москва; б) территория в Калужской области

В результате совмещенния получен топографический план (рис. 8).

Контрольные измерения в положении на плане предметов и контуров местности с четкими очертаниями относительно ближайших точек съемочного обоснования показали хорошее соотвествие требованиям Инструкции [5].
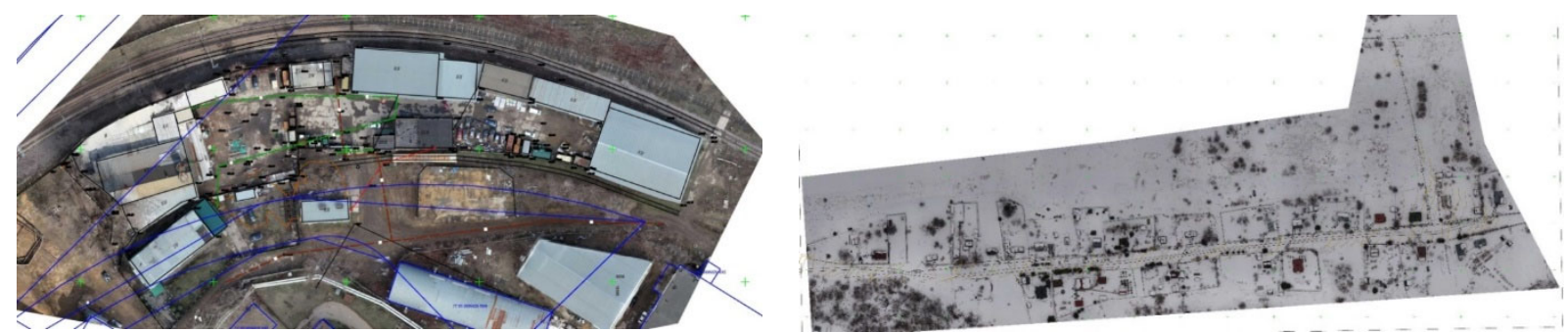

Рис. 8. Совмещенный фотоплан с топографической съемкой

Расчет экономической эффективности использования современных методов был выполнен путем сравнительной стоимости полного объема работ разным оборудованием: спутниковым оборудованием Trimble R8s и беспилотником DJI ProPhantom 4 Pro. B качестве оценки экономической эффективности спутниковых методов и использования беспилотника была учтена себестоимость используемого оборудования и временные затраты.

Расчет показал, что на выполнение полевых работ при помощи спутникового оборудования и беспилотника было затрачено в 5 раз меньше человекодней по сравнению с использованием только спутникового оборудования, а на камеральные работы - в 4 раза меньше,

Таким образом, легальное использование беспилотников в геодезии и кадастре будет способствовать повышению эффективности работ, сокращая время, повышая достоверность результатов [6]. Преимущества беспилотного аппарата над традиционными методами инструментальной съемки очевидны: для БПЛА не существует труднодоступных мест, водных препятствий, особенностей рельефа, размеров территорий. 


\section{БИБЛИОГРАФИЧЕСКИЙ СПИСОК}

1. Дементьев В. Е. Современная геодезическая техника и ее применения: Учебное пособие для вузов. - Изд. 2-е. - М.: Академический Проект, 2018. - 591 с.

2. Инструкция по топографической съемке в масштабах 1:5000, 1:2000, 1:1000, 1:500 ГКИНП-02-033-82.

3. ГКИНП-09.-32-80. Основные положения по аэрофотосъемке, выполняемой для создания и обновления топографических карт и планов.

4. Ворошилов А.П. Спутниковые системы и электронные тахеометры: Учебное пособие. Челябинск: АКСВЕЛЛ, 2007.-163 с.

5. ГКИНП-45. Руководство по обновлению топографических карт".

6. Постановление Правительства РФ от 25 мая 2019 г. N 658 «Об утверждении Правил учета беспилотных гражданских воздушных судов.... ввезенных в Российскую Федерацию или произведенных в Российской Федерации».

(С) И. А. Басова, П. В. Анисимов, 2021 